\title{
DE NUEVO SOBRE LA CONCEPCIÓN ESTÁNDAR Y LA CONCEPCIÓN REALISTA DEL DERECHO \\ (RESPUESTA A LA RÉPLICA DE RAFAEL HERNÁNDEZ MARÍN)
}

\begin{abstract}
. En mi artículo «Los presupuestos ontológicos del Derecho» critiqué un trabajo de Rafael Hernández Marín, «La concepción estándar y la concepción realista del Derecho», publicado en el número XII del Anuario de Filosofía del Derecho. Mi artículo ha sido objeto, a su vez, de una respuesta por parte de este mismo autor. En estas páginas me correspondería a mí iniciar una nueva contraargumentación, continuando así un cruce de artículos y notas sobre los argumentos de uno y otro. Sin embargo, no voy a insistir en la defensa de mis argumentos (que sigo manteniendo en lo fundamental) o en la crítica de los argumentos de Rafael Hernández Marín, y ello por dos razones. La primera razón es que estos ejercicios de réplicas y contrarréplicas corren el peligro (por uno u otro lado) de repetir una y otra vez los mismos argumentos, con ropajes nuevos o desde perspectivas distintas, o de atrincherarse en posturas dogmáticas, lo que seguramente ni logra convencer al interlocutor ni interesar a posibles lectores. La segunda razón es que la respuesta de Rafael Hernández Marín me desanima a continuar el debate, pues -sorprendentemente- comienza con expresiones que podrían entenderse más como una descalificación personal que como argumentos contra mis tesis, y si esto fuera así se estaría llevando la discusión fuera del terreno intelectual.

Por ello me voy a limitar a dos puntos. El primero, tratar de mostrar que -en contra de su opinión- no he cometido ninguna deformación de las tesis de Hernández Marín, tal como venían expresadas en su artículo. El segundo, mostrar algunas incomprensiones de Rafael Hernández Marín hacia mi texto. Si alguna justificación tiene de cara al lector que proceda así, ésta no es tratar de decir la última palabra (aunque creo que estos intercambios de réplicas y contrarréplicas no deben eternizarse), sino confiar en que de esta manera queden más claros los términos de esta discusión.
\end{abstract}

2. De las muchas tesis de Rafael Hernández Marín que deformo en mi crítica («deforma tantas ideas mías, y algunas de ellas las deforma tanto...» 
escribe) sólo encuentro mencionadas en su réplica tres (el resto de puntos me parecen simplemente divergencias de opiniones). Veámoslas:

2.1. Una de las tergiversaciones que presuntamente cometo guarda relación con los usos lingüísticos. Mis falsificaciones consisten en este caso en dos: La primera, en no haber entendido que el siguiente párrafo:

«los usos lingüísticos relativos a la palabra "Derecho" establecen dos cosas: a) que la Constitución, el Código Civil, etc. forman parte del Derecho; y b) qué es lo que dicen (literalmente) los artículos o apartados de la Constitución, del Código Civil, etc.»

ha de interpretarse como:

«Según estos usos, propios de los juristas y de los no juristas, relativos a la palabra "Derecho", del Derecho español actual forma parte "algo", cuyo "contenido" es (literalmente) el siguiente: "El nacimiento determina la personalidad"».

Pero Rafael Hernández Marín añade en su réplica: «admito que en mi artículo no expresé la tesis expuesta con la debida claridad», lo que explicaría mi supuesta «tergiversación».

El segundo error mío consiste en haber sugerido que los usos lingüísticos relevantes en este caso son, fundamentalmente, los de los juristas, y no los de aquellos que no son juristas. Rafael Hernández Marín sostiene lo contrario (y aporta nuevos e importantes argumentos, pero no decisivos, al igual que no lo eran los míos), y piensa que «tampoco Daniel González Lagier se ha esforzado en entender mi alusión al respeto por los usos lingüísticos». Pero que haya sostenido en mi artículo una tesis contraria no quiere decir que haya interpretado mal la suya, pues no parece una discusión que tenga una solución obvia y evidente (sólo si fuera así podría pensarse que no aceptar la tesis equivale a no entenderla o malinterpretarla).

2.2. Una segunda deformación tiene que ver con las referencias de Rafael Hernández Marín al «texto de la ley». En mi artículo sostuve que «el hecho de que Hernández Marín se refiera genéricamente al "texto de la ley", sin especificar a cuál de estos textos, puede hacer pensar que esta expresión hace referencia más bien (como ocurre con su uso común) a una abstracción a partir de esos textos realmente existentes». Rafael Hernández Marín objeta que «en ningún caso (ni en el artículo, ni en el citado libro) mis referencias al texto de la ley "hacen pensar" que ese texto es una "abstracción", como dice Daniel González Lagier [aunque mi tesis era más débil: dije "pueden hacer pensar"]». Pero no aclara por qué debemos evitar esta conclusión: la expresión «texto de la ley» se utiliza (o puede pensarse que se utiliza) como una referencia a una clase, en lugar de como una referencia a un texto concreto, si se afirma que la ley se identifica con el texto de la ley y no se especifica con cuál. Ello hace que sea conveniente (aunque, como dice Rafael Hernández Marín, quizá no necesario) para una teoría como ésta especificar 
cuál es este texto (y Rafael Hernández Marín anuncia la publicación de un libro donde se aclaran estas cuestiones).

Pero esta cuestión guarda relación con un «desafío» que este autor me lanza en su réplica: «le desafío -escribe- a que indique un solo ejemplo de tales fenómenos [aquéllos que la concepción realista no puede explicar y sí la concepción estándar]; y le doy un amplio plazo para ello: todo el tiempo que desee». Agradezco el plazo, pero no deseo más tiempo. En mi artículo sugerí que la concepción realista distorsiona el proceso de la actividad judicial, básicamente porque no logra dar cuenta de la pretensión de corrección con la que los jueces solucionan los casos difíciles, pero Rafael Hernández Marín rechaza este supuesto (por cierto, y dicho sea de paso, comienzo a sospechar que no decimos cosas tan distintas, y que para aclarar este punto deberíamos discutir acerca de qué entendemos por «conciencia» o «prudencia» de los jueces). Sin embargo, Rafael Hernández Marín me pide un solo ejemplo: pues bien, el no poder precisar cuál es el texto de la ley y las cuestiones relacionadas con ello constituyen un problema que la concepción estándar no plantea, y que -como reconoce Rafael Hernández Marín- debe solucionar su teoría realista. Quedamos, pues, a la espera del libro anunciado por Rafael Hernández Marín para saber si he superado el «desafío» que este autor me lanza.

2.3. He dejado para el final la principal deformación que, al parecer, cometo, esto es, la de atribuir a Rafael Hernández Marín la tesis de que «sólo existen los objetos físicos» (y otras afirmaciones que son variaciones sobre el mismo tema). Tiene razón Rafael Hernández Marín si en mi artículo he dado la impresión de que él sostiene que, en el mundo, sólo hay objetos físicos. Mi afirmación no debe entenderse, sin embargo, de manera descontextualizada, sino en el contexto de un debate sobre qué tipo de entidades existen en el «mundo del Derecho». Pues bien, Rafael Hernández Marín afirma en su artículo inicial « $1^{\circ}$ ) que no hay más Derecho que el Derecho positivo; $2^{\circ}$ ) que no hay más Derecho que la ley; $3^{\circ}$ ) que no hay más ley que el texto de la ley; $4^{\circ}$ ) que ese texto legal es un hecho, un objeto físico» ${ }^{1}$. Rafael Hernández Marín aclara en su réplica que esta última frase debe entenderse como «ese texto legal es un hecho, concretamente, un objeto físico», y no como «ese texto legal es un hecho, o sea, un objeto físico». Pero se entienda como se entienda esta frase, del párrafo anteriormente citado se puede concluir (sin ninguna deformación) que, a propósito del Derecho, nuestro autor adopta como paradigma el modo de existencia de los objetos físicos. En su réplica, además, afirma que «la concepción realista del Derecho

\footnotetext{
348.

${ }^{1}$ Rafael Hernández Marín, «La concepción estándar y la concepción realista del Derecho», pág.
} 
es una concepción factualista del Derecho, por sostener que las reglas jurídicas son objetos físicos». Añade a continuación que otras teorías factualistas identifican las normas con eventos. No lo dudo, pero estamos hablando de su concepción del Derecho; además, él rechaza esas otras concepciones, lo que me lleva a suponer que, para Rafael Hernández Marín, una concepción factualista del Derecho adecuada o correcta debe dejar fuera -como hace la suya- a los eventos.

Pero, obviamente, en mi artículo pretendí ir algo más allá de la mera constatación de que para la concepción factualista (es decir, para la concepción factualista de Rafael Hernández Marín ${ }^{2}$ ) las entidades que componen el Derecho son objetos físicos, que es en lo que consiste el núcleo de nuestra discusión. Quise sugerir (pero quizá no quedó claro) que sólo se llega a esta tesis si se parte de una especie de «prejuicio» en contra de la admisión de eventos en el Derecho. Este prejuicio se manifiesta en que en el artículo «La concepción estándar y la concepción realista del Derecho» no se analiza por qué la costumbre, que consiste en una regularidad de comportamientos -es decir, eventos- junto con ciertas actitudes psicológicas -que pueden ser explicadas como eventos-, no forma también parte del Derecho. Esta cuestión no se menciona en aquel artículo y se despacha en la réplica de Rafael Hernández Marín con dos argumentos: el primero -incontestable- que las normas consuetudinarias «ni son hechos, ni son reducibles a hechos; de la misma manera que el ángel de la guarda o la fuente de la eterna juventud no son hechos, ni reducibles a hechos». El segundo tiene que ver con mi propuesta de definición de las reglas consuetudinarias (tomada de Hart a través de Juan Carlos Bayón ${ }^{3}$ ); dice así: «si aceptáramos la «reducción» sugerida

${ }^{2}$ Una fuente de malentendidos entre Rafael Hernández Marín y yo mismo me parece que puede haber sido de índole terminológica, pues es cierto que en mi artículo hice algunas afirmaciones sobre la concepción factualista sin precisar en todo momento que me refería en concreto a la concepción factualista de Rafael Hernández Marín.

${ }^{3}$ Es la siguiente: «Sintéticamente, para Hart se puede afirmar que existe en el grupo G una regla social a tenor de la cual "todo $S$ debe hacer $\oslash$ en las circunstancias C", si y sólo si: 1) Existe de hecho una cierta regularidad de comportamiento, es decir, dentro de $\mathrm{G}$ la mayor parte de los $\mathrm{S}$ hacen $ə$ en la mayor parte de las ocasiones en las que concurren las circunstancias $\mathrm{C}$; 2) las desviaciones respecto al comportamiento regular son motivo de crítica (...);3) las conductas consistentes en manifestar esas reacciones críticas no suscitan a su vez reacciones críticas ulteriores por parte de los miembros de $\mathrm{G}$ (...); 4) los miembros de G -o al menos algunos de ellos- adoptan una "actitud crítica reflexiva" que se manifiesta en el uso del lenguaje normativo (esto es, de términos deónticos como "deber") y en apelaciones a la regla en cuestión para justificar a) por qué ellos mismos -si pertenecen a la clase de sujetos $\mathrm{S}$ - hacen ø cuando concurren las circunstancias $\mathrm{C}$; b) por qué critican a los $\mathrm{S}$ cuando se desvían de esa pauta de conducta; y c) por qué no consideran a su vez objeto de crítica la manifestación de esas reacciones críticas» (Juan Carlos Bayón, La normatividad del Derecho: Deber jurídico y razones para la acción, Centro de Estudios Constitucionales, 1991, pág. 449). 
por Daniel González Lagier, junto a los hechos descritos en el definiens de la definición «reductora», tendríamos además una regla social o consuetudinaria (cuya naturaleza ontológica seguiría siendo dudosa), que ordena o prohíbe algo, y a la que alude el definiendum. Dicho con un ejemplo, la citada "reducción" es como "reducir" la cólera de Júpiter a los truenos, mediante la siguiente definición "reductora": "Júpiter está encolerizado sí y sólo si truena"». Reproduzco este argumento para confesar que (aunque pueda ser elemental) yo no lo entiendo: de acuerdo con el argumento, en el definiens no hay sólo hechos, sino también una regla consuetudinaria, pero no veo cuál de los cuatro puntos del definiens puede ser tal regla social, y Rafael Hernández Marín no lo aclara. Si, en cambio, lo que este argumento afirma es que estos cuatro puntos presuponen la existencia de una regla social, entonces la definición se ha entendido mal, pues lo que ésta quiere decir no es que la regla social se manifieste en estos cuatro hechos, sino que éstos hechos son las condiciones de existencia de la regla social.

En definitiva, por todo ello, sigo pensando, como afirmé en mi primer artículo, que «el problema básico de la concepción de Hernández Marín [que es una concepción sobre el Derecho, o al menos ésa es la que estamos discutiendo] es haber adoptado un concepto homogéneo de "existencia", que toma como paradigma de existencia el modo de existencia de los objetos físicos».

3. Entre otros, quisiera destacar, muy brevemente, tres puntos de mi artículo que me parece que Rafael Hernández Marín ha entendido de forma distinta a la pretendida por mí, lo que quizá haya aumentado su sensación de que fui poco fiel a sus tesis:

3.1. En mi artículo propuse cuatro formulaciones distintas de cómo podría entenderse la objeción según la cual la concepción estándar es idealista. La primera de ellas pretendía ser reflejo de la opinión de Rafael Hernández Marín. Esta formulación decía: «La concepción estándar es idealista porque admite la existencia de entidades que no son objetos físicos». Rafael Hernández Marín afirma que esta formulación sólo expresa parcialmente lo que él quería decir. Sin embargo, a mí me parece que esta formulación viene implicada por el siguiente párrafo escrito por él: «En cuanto se admita un Derecho distinto del Derecho positivo (esto es, en cuanto se admita un Derecho natural); o bien un Derecho positivo distinto de la ley (como los principios generales del Derecho o el Derecho consuetudinario); o bien se rechace la identificación entre la ley y el texto de la ley se está sosteniendo, al menos parcialmente, una concepción idealista, no empírica, del Derecho» ${ }^{4}$. De acuerdo con este párrafo, si se afirma que existe un Derecho

\footnotetext{
${ }^{4}$ «La concepción estándar y la concepción realista del Derecho», pág. 351.
} 
positivo distinto de la ley o no se identifica a ésta con el texto de la ley, se admite una concepción idealista. Ahora bien, como el texto de la ley es un objeto físico (y dado que no se ve qué otros objetos físicos pueden ser relevantes como entidades jurídicas), estas afirmaciones implican mi primera formulación: la concepción estándar (que es una concepción sobre el Derecho) es una concepción idealista porque admite la existencia (en el Derecho) de entidades que no son objetos físicos (esto es, de entidades distintas al texto de la ley, entendido como lo hace Rafael Hernández Marín).

A partir de esta formulación, pretendí (1) señalar la conveniencia de abrir la posibilidad a la admisión de hechos o eventos en el Derecho (y recurrí a algunos párrafos de Russell para mostrar algunas diferencias entre objetos y hechos, lo que no implica aceptar toda la ontología del atomismo lógico); (2) señalar la diferencia entre «lo que realmente existe» y «lo que creemos que realmente existe» (lo que no implica asumir la existencia de dos mundos: sino del mundo y de las creencias sobre el mismo) y la conveniencia de adoptar una perspectiva científica (es decir, de guiarse por las creencias de los científicos acerca de lo que existe); y (3) mostrar la influencia del potencial explicativo y práctico de nuestras creencias acerca de lo que existe (y las de los científicos) a la hora de escoger una u otra teoría. Cada una de las argumentaciones tendentes a sostener estas tesis concluía con la conveniencia de reformular la objeción de idealismo contra la concepción estándar, para adaptarla a las nuevas perspectivas que se abrían en cada caso. Por ello, hablé en todo momento de formulaciones o, incluso, reformulaciones de la objeción de idealismo, y utilicé expresiones como «si modificamos consecuentemente el argumento contra la concepción estándar...», «tendríamos que reformular el argumento como sigue...». En ningún momento sostuve que se trataba de formas distintas de interpretar la objeción de Rafael Hernández Marín (salvo por lo que se refiere a la primera formulación). Por ello, este autor muestra haberme entendido mal cuando afirma que «las otras tres interpretaciones o formulaciones que Daniel González Lagier hace de mi tesis "la concepción estándar del Derecho es idealista" no se aproximan, ni remotamente, a mi pensamiento». Nunca lo pretendieron.

3.2. Tampoco afirmé en ningún momento, ni creo que se desprenda de mis tesis, que una concepción idealista del Derecho es preferible a una concepción factualista. Rafael Hernández Marín no señala dónde digo tal cosa, ni creo que pueda hacerlo, así que no comprendo por qué escribe que «a Daniel González Lagier, como a la mayoría de los juristas, esta conclusión le parece "contraintuitiva", "chocante", "extraña", etc. Según él, el que una concepción del Derecho sea una concepción empírica del Derecho no es algo digno de elogio. Al parecer, es mucho más intuitivo, racional, plausible, 
elogiable, etc., sostener lo contrario, o sea, las dos tesis antes citadas: que existe un mundo de ideas y que allí moran las entidades jurídicas». Ciertamente, he usado expresiones como «extraña», «chocante» y «contraintuitiva», pero no en contra de cualquier concepción empírica del Derecho, sino exclusivamente en contra de la concepción factualista del Derecho de Rafael Hernández Marín (que me parece la más «chocante», «extraña» y «contraintuitiva» de las que conozco). Quizá haya que recordar a este autor algo de lo que parece haberse olvidado (olvidado sólo a propósito de estas críticas, pero que él mismo me recuerda en otro momento): que no es el único representante de las teorías empíricas del Derecho, por lo que no puede extender mis críticas a su concepción al resto de concepciones empíricas, factualistas o incluso realistas (pues la concepción realista del Derecho de Rafael Hernández Marín no es la única concepción realista del Derecho).

Precisamente porque creo que debe rechazarse el idealismo en el ámbito del Derecho (y no sólo en él), he tratado de mostrar que es falso que la concepción estándar sea necesariamente idealista y -como el propio Rafael Hernández Marín menciona críticamenteque los principios generales del Derecho y las reglas consuetudinarias no tienen por qué entenderse necesariamente como entidades ideales (mis argumentos siguen siendo los mismos, por lo que no voy a reproducirlos). Me niego a admitir que las alternativas sean, o bien ser idealista, o bien acoger la concepción de Rafael Hernández Marín, sin considerar antes otras posturas empiristas.

3.3. Por último, la primera objeción de Rafael Hernández Marín. Considera este autor que haber titulado mi artículo «Los presupuestos ontológicos del Derecho» es un error, pues nuestra discusión no versa acerca de cuáles son los presupuestos ontológicos del Derecho, sino acerca de si éstos son correctos. Pero esta objeción presupone que «Los presupuestos ontológicos del Derecho» ha de interpretarse como «¿Cuáles son los presupuestos ontológicos del Derecho?», y no como «¿Son correctos los presupuestos ontológicos del Derecho?». Pero, ¿por qué habría de ser así? El título de mi artículo sólo dice que vamos a hablar sobre los presupuestos ontológicos del Derecho, y podremos hablar sobre cuáles son o sobre si son correctos. El título no prejuzga sobre cuál de las dos cosas vamos a hablar, salvo que se haga una injustificada interpretación restrictiva o parcial.

4. No quisiera concluir sin plantearme la siguiente cuestión: ¿Qué razones pueden explicar los malos entendidos por parte de uno u otro? (hasta tal punto que en algún momento parece que estemos hablando de artículos distintos). Rafael Hernández Marín me achaca a mí todos los malentendidos y sugiere que pueden deberse a la falta de buenas intenciones o a la falta de la debida diligencia. Pues bien, aunque yo sé que no me ha faltado 
buena intención (¿por qué habría de faltarme?) y creo -no: estoy seguro que tampoco la debida diligencia, no tengo inconveniente en asumir por los dos todo el peso de la culpa ni en cargar los malentendidos en la cuenta de mi propia torpeza tanto al interpretar a Rafael Hernández Marín como al expresarme en mi artículo (un beneficio de la duda que él no me ha concedido, sin embargo). Pero como me resisto a considerar mi torpeza como absoluta incompetencia, encuentro consuelo en pensar que la cuestión de «los presupuestos ontológicos del Derecho» (en el sentido de «¿son correctos los presupuestos ontológicos del Derecho?») es un tema sumamente difícil. Aunque tengo fuertes intuiciones -compartidas por la mayoría de los juristas- acerca de que mi postura es la correcta, y aunque actúe en mi trabajo cotidiano asumiendo sin más reflexión «los presupuestos ontológicos del Derecho» (ahora en el sentido de «¿cuáles son los presupuestos ontológicos del Derecho?») de la concepción estándar, he de reconocer que no resulta fácil abogar con sólidos argumentos filosóficos por esta postura (pero tampoco, por cierto, por la contraria). Éste es un reto que todavía hemos de vencer, y recordárnoslo es uno de los méritos de la obra de Rafael Hernández Marín. 